\title{
EXTENDED X-RAY ABSORPTION FINE STRUCTURE EVIDENCE FOR HOMOPOLAR BONDING IN AMORPHOUS Cd-As AND Zn-P
}

\author{
A. Burian \\ Department of Solid State Physics, Polish Academy of Sciences \\ Wandy 2, 41-800 Zabrze, Poland
}

\begin{abstract}
Local atomic arrangement in evaporated amorphous $\mathrm{Cd}-\mathrm{As}$ and $\mathrm{Zn}-\mathrm{P}$ films was investigated by extended X-ray absorption fine structure. Results of modelling indicate that bonds between atoms of the same kind occur for both $(\mathrm{Cd}, \mathrm{Zn})$-rich and (As,P)-rich compositional regions. This specific chemical ordering, much alike to that in the corresponding crystalline polymorphs, appears to play a predominant role in determining of the local structures in these materials.
\end{abstract}

PACS numbers: $61.10 . \mathrm{Lx}, 61.55 . \mathrm{Hg}, 78.30 . \mathrm{Fs}$

In the recent years the extended X-ray absorption fine structure (EXAFS) technique has proved to be very powerful tool for local structure analysis of disordered materials like amorphous semiconductors [1-3]. The main advantage of this technique is its ability to probe the environment of a selected atomic species. Therefore, the use of EXAFS is especially of interest in case of multicomponent materials in which different partial radial distribution functions (RDF) are merged in the near-neighbour coordination sphere.

For $\mathrm{A}^{\mathrm{III}} \mathrm{B}^{\mathrm{V}}$ amorphous semiconductors as $\mathrm{Ga}-\mathrm{P}$ and $\mathrm{In}-\mathrm{P}$ it was found that A-A, B-B bonds appear to be formed apart from A-B bonds, which should be favoured in these systems [1, 2]. Bonds between alike atoms are called "wrong bonds" and their detailed characterization is necessary to interpret correctly the electronic properties of these materials. The previously performed large-angle X-ray scattering (LAXS) investigations on the $\mathrm{Cd}-\mathrm{As}$ and $\mathrm{Zn}-\mathrm{P}$ amorphous films showed that the tetrahedral models, in which the partial $\mathrm{Cd}(\mathrm{Zn})-\mathrm{Cd}(\mathrm{Zn}), \mathrm{Cd}(\mathrm{Zn})-\mathrm{As}(\mathrm{P})$ and $\operatorname{As}(P)-A s(P)$ contributions are involved in the first RDF peak, account for the experimental data $[4,5]$.

In order to study precisely the environment of individual atoms, the EXAFS experiments were carried out at both the As and $\mathrm{Zn} K$-edges for the Cd-As films with composition from 45 to 82 at\% $\mathrm{As}$ and the $\mathrm{Zn}-\mathrm{P}$ films containing 47 and 68 at\% P. The measurements were performed on the DCI synchrotron radiation facility at LURE (Orsay, France). The experiments and the data treatment were described in detail elsewhere [6-8]. 
The oscillatory part of the absorption coefficient in the single-scattering approximation, assuming Gaussian distribution of interatomic distances, is given by the expression [6]:

$$
X(k)=\sum_{j} S_{i} N_{j} F_{j}(k) \exp \left(-2 k^{2} \sigma_{j}^{2}\right) \exp \left(-2 r_{j} / \lambda_{j}\right) \frac{\sin \left[2 k r_{j}+\Phi_{i j}(k)\right]}{k r_{j}^{2}},
$$

in which $k=\left[8 \pi^{2} m\left(E-E_{0}\right) / h^{2}\right]^{1 / 2}, m$ is the mass of electron, $h$ is Plank's constant, $\mathrm{E}_{0}$ is the energy threshold, $S_{i}$ is the amplitude scaling factor included to consider multielectron excitation at absorbing atom $i, F_{j}$ is the backscattering amplitude from $N_{j}$ neighbours of the $j$-th type at distance $r_{j}$ from absorbing atom, $\lambda_{j}$ is the electron free path, $\sigma_{j}$ is the standard deviation of the interatomic distance, $\Phi_{i j}$ denotes the total phase shift.

Several models were tested to reconstruct the first coordination sphere around As and $\mathrm{Zn}$ atoms [7, 8]. The least-squares fitting procedure was applied to analyse the measured spectra. The resulting parameters together with the fitting uncertainties are collected in Table $\mathrm{I}$.

TABLE I

The best fit parameters for the Cd-As amorphous films.

\begin{tabular}{|c|c|c|c|c|c|c|c|}
\hline \multicolumn{2}{|c|}{ Sample } & \multirow{2}{*}{\begin{tabular}{|c}
$\begin{array}{c}r[\AA] \\
( \pm 0.03)\end{array}$ \\
2.43
\end{tabular}} & \multirow{2}{*}{$\begin{array}{c}N \\
( \pm 0.5) \\
0.90\end{array}$} & \multirow{2}{*}{$\begin{array}{c}\sigma[\AA] \\
( \pm 0.02) \\
005\end{array}$} & $\begin{array}{c}S \\
( \pm 0.2)\end{array}$ & $\begin{array}{c}E_{0}[\mathrm{eV}] \\
( \pm 2)\end{array}$ & \multirow[t]{2}{*}{$\bar{R}$} \\
\hline \multirow{3}{*}{$\mathrm{Cd}_{55} \mathrm{As}_{45}$} & As-As & & & & \multirow{3}{*}{0.85} & \multirow{3}{*}{2.00} & \\
\hline & $\mathrm{As}-\mathrm{Cd}$ & 2.69 & 2.10 & 0.08 & & & \multirow[t]{2}{*}{0.0017} \\
\hline & $\mathrm{As}-\mathrm{Cd}$ & 2.91 & 1.00 & 0.11 & & & \\
\hline \multirow{3}{*}{$\mathrm{Cd}_{50} \mathrm{As}_{50}$} & As-As & 2.44 & 1.00 & 0.06 & \multirow{3}{*}{0.70} & \multirow{3}{*}{1.05} & \multirow{3}{*}{0.0055} \\
\hline & $\mathrm{As}-\mathrm{Cd}$ & 2.68 & 2.00 & 0.10 & & & \\
\hline & $\mathrm{As}-\mathrm{Cd}$ & 2.92 & 1.00 & 0.11 & & & \\
\hline \multirow{3}{*}{$\mathrm{Cd}_{36} \mathrm{As}_{64}$} & As-As & 2.42 & 1.75 & 0.06 & \multirow{3}{*}{0.70} & \multirow{3}{*}{2.00} & \multirow{3}{*}{0.0072} \\
\hline & $\mathrm{As}-\mathrm{Cd}$ & 2.66 & 1.50 & 0.07 & & & \\
\hline & $\mathrm{As}-\mathrm{Cd}$ & 2.76 & 0.75 & 0.14 & & & \\
\hline \multirow{3}{*}{$\mathrm{Cd}_{26} \mathrm{As}_{74}$} & $\mathrm{As}-\mathrm{As}$ & 2.44 & 2.50 & 0.07 & \multirow{3}{*}{0.87} & \multirow{3}{*}{1.20} & \multirow{3}{*}{0.0047} \\
\hline & & & & & & & \\
\hline & $\mathrm{As}-\mathrm{Cd}$ & 2.67 & 1.50 & 0.10 & & & \\
\hline \multirow{3}{*}{$\mathrm{Cd}_{18} \mathrm{As}_{82}$} & $\mathrm{As}-\mathrm{As}$ & 2.44 & 3.00 & 0.07 & \multirow{3}{*}{0.70} & \multirow{3}{*}{0.70} & \multirow{3}{*}{0.0017} \\
\hline & & & & & & & \\
\hline & $\mathrm{As}-\mathrm{Cd}$ & 2.67 & 1.00 & 0.07 & & & \\
\hline
\end{tabular}

In order to fit the experimental data for the Cd-rich compositions it was necessary to introduce two slightly different As-Cd subshells and one As-As shell. For the films containing 74 and 82 at\% As the two-shell models with one As-As 

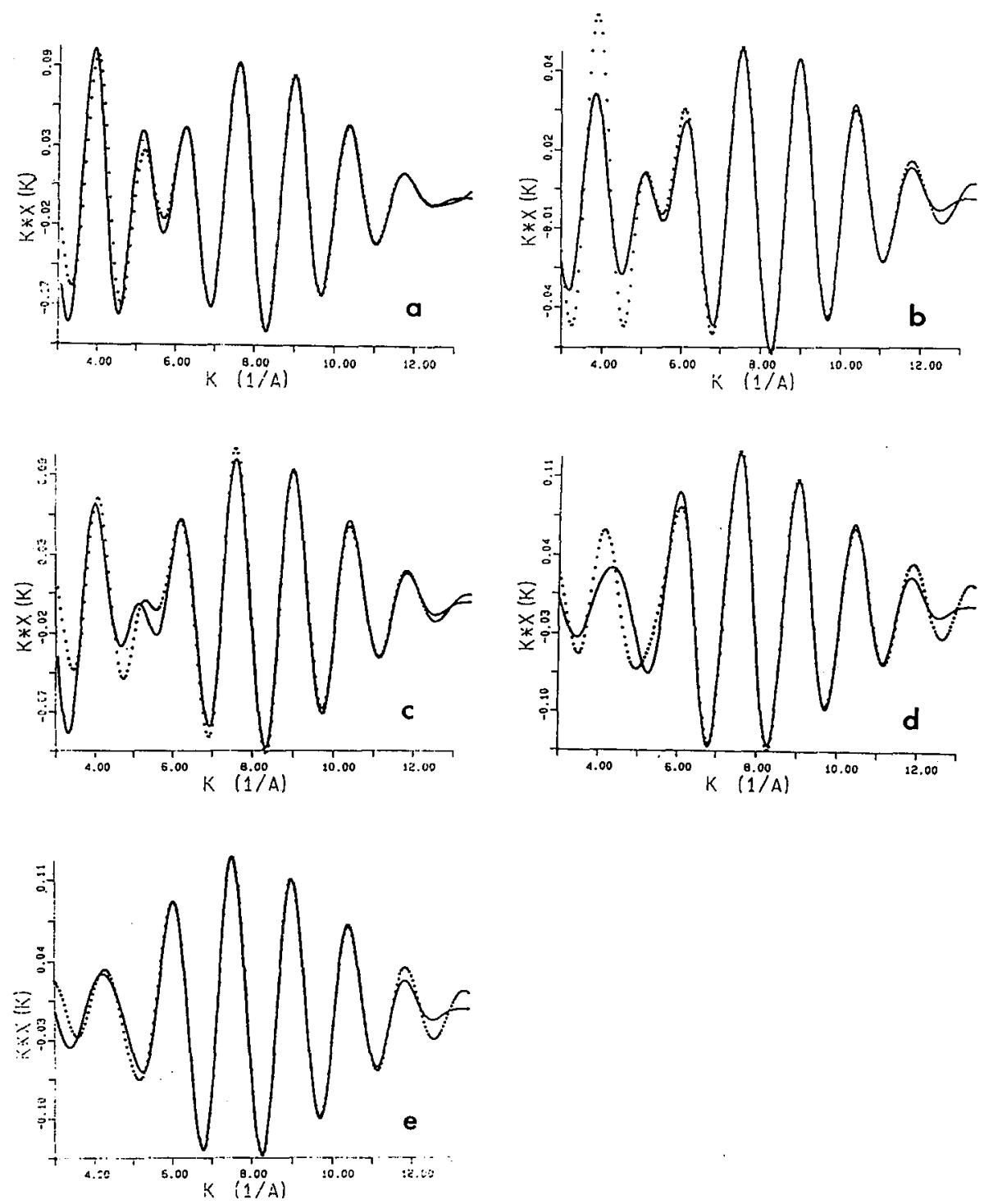

Fig. 1. The $k X(k)$ calculated functions (the three-shell model for (a) $\mathrm{Cd}_{55} \mathrm{As}_{45}$, (b) $\mathrm{Cd}_{50} \mathrm{As}_{50}$, (c) $\mathrm{Cd}_{36} \mathrm{As}_{64}$ and the two-shell model for (d) $\operatorname{Cd}_{26} \mathrm{As}_{74}$, (e) $\mathrm{Cd}_{18} \mathrm{As}_{82}$ - dotted line) superimposed on the experimental data (solid line).

and one As-Cd shell matches satisfactorily the data. The As-As distances are the same within the errors for all compositions. The appreciable contraction of the As-Cd distance is observed for the As-rich films. Such a trend was found from the LAXS studies and was explained by the structural change [4].

For the films containing 45 and 50 at\% As the distorted tetrahedral model 
based on the CdAs type structure [4] describes satisfactorily As environment. The near-neighbours coordination sphere of the films at 74 and 82 at\% As looks much alike to that of crystalline $\mathrm{CdAs}_{2}$. The compositions close to 64 at\% As can be regarded as intermediate between two $\mathrm{Cd}$ - and As-rich structural regions. The results of the fits are superimposed on the experimental data in Fig. 1.

Assuming tetrahedral coordination and the bond consistency condition: $c_{A} N_{A-B}=c_{B} N_{B-A}\left(c_{A}\right.$ and $c_{B}$ are the atomic concentrations), the presence of the $\mathrm{Cd}-\mathrm{Cd}$ contribution is expected for the $\mathrm{Cd}$-rich compositions. In order to verify this hypothesis, the environment of $\mathrm{Zn}$ atoms was studied. The best fit parameters are shown in Table II. The threshold energy difference $\Delta E_{0}$ was evaluated

\section{TABLE II}

The best fit parameters for the $\mathrm{Zn}-\mathrm{P}$ amorphous films.

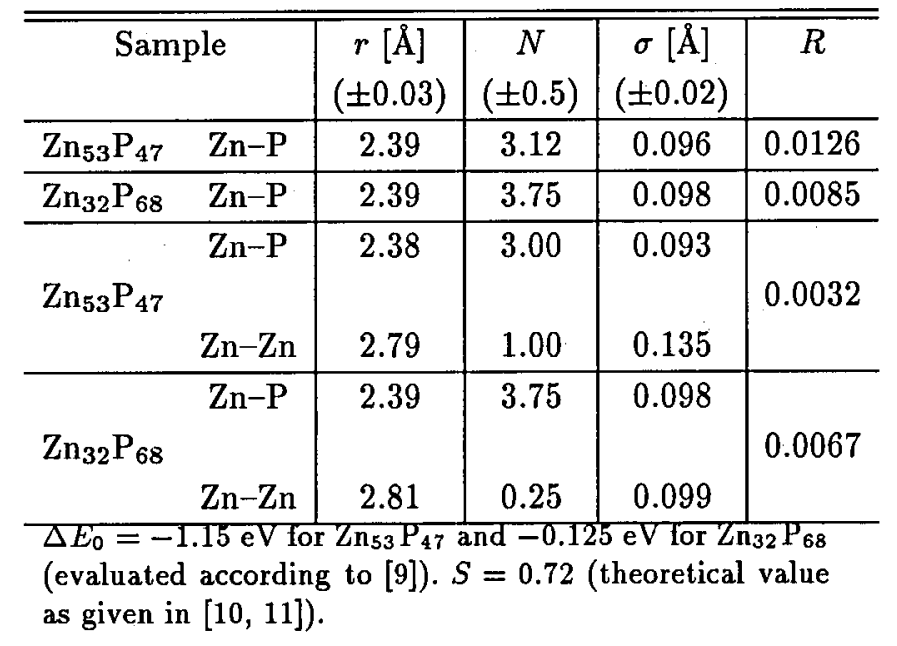

using the method proposed by Lee and Beni [9]. The amplitude scaling factor $S$ was taken from Carlson's tables [10], experimentally verified by Stern, Bunker and Heald [11].

For the $\mathrm{Zn}_{53} \mathrm{P}_{47}$ film the fit yielded $1 \mathrm{Zn}$ atom and $3 \mathrm{P}$ at around $\mathrm{Zn}$. As the content of $\mathrm{P}$ increased to 68 at\%, the number of the $\mathrm{Zn}-\mathrm{Zn}$ bonds is almost completely reduced within method precision and the fit converges to the $N_{\mathrm{Zn}-\mathrm{P}}$ coordination number close to four. Adding the $\mathrm{Zn}-\mathrm{Zn}$ contribution weighted by 0.25 improves slightly the fit when compared with the one-shell $\mathrm{Zn}-\mathrm{P}$ model [7]. The best fits of the two-shell model are shown in Fig. 2.

Changing of the chemical composition of the $\mathrm{Cd}-\mathrm{As}$ and $\mathrm{Zn}-\mathrm{P}$ amorphous films leads to two different types of local ordering. The obtained coordination numbers around both $\mathrm{As}$ and $\mathrm{Zn}$ indicate that II-II, V-V and II-V bonds are formed for the $\mathrm{Cd}(\mathrm{Zn})$-rich films. Such bonds are characterictic of the II-V compounds with 1:1 stoichiometry and their nature departs somewhat from the usual concept of semiconducting bond $[4,5]$. 

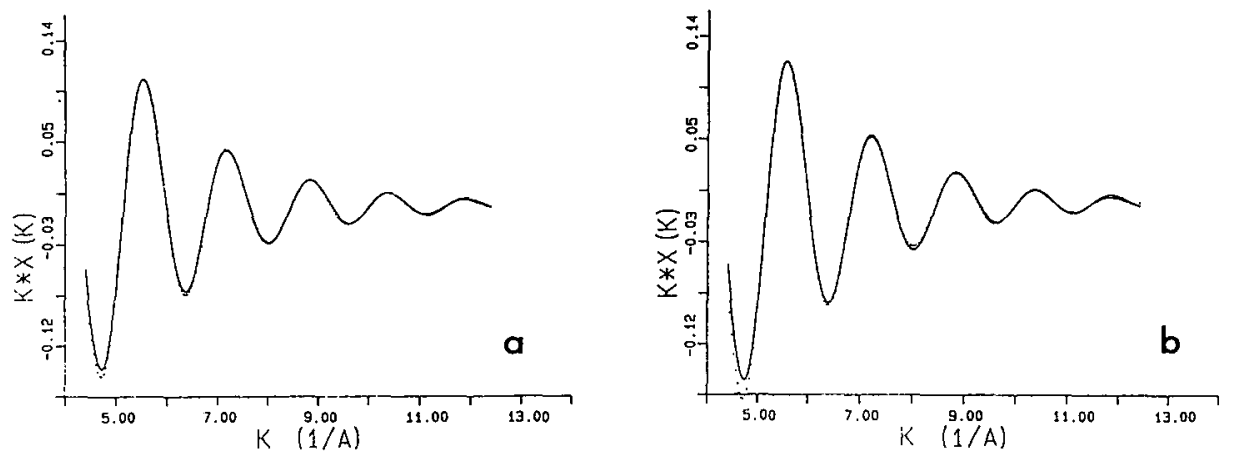

Fig. 2. The two-shell best fit (dotted line) and experimental $k X(k)$ (solid line) functions for (a) $\mathrm{Zn}_{53} \mathrm{P}_{47}$ and (b) $\mathrm{Zn}_{32} \mathrm{P}_{68}$.

For the $\mathrm{As}(\mathrm{P})$-rich films the metal-metal contribution is practically excluded. This tendency can be understood considering the bond scheme in the corresponding 1:2 crystalline polymorphs, in which the $\mathrm{As}(\mathrm{P})$ atoms are coordinated by two $\mathrm{As}(\mathrm{P})$ and two $\mathrm{Cd}(\mathrm{Zn})$, whereas $\mathrm{Cd}(\mathrm{Zn})$ has $4 \mathrm{As}(\mathrm{P})$ as the nearest neighbours $[4,5]$.

The bonds between alike atoms are not considered in terms of chemical disorder and the amorphous II-V systems can be regarded as a new family of non-crystalline semiconductors with the specific structure.

\section{References}

[1] A.M. Flank, P. Lagarde, D. Udron, S. Fisson, A. Gheorghiu, M.L. Theye, J. Non-Cryst. Solids 97\&98, 435 (1987).

[2] D. Udron, A.M. Flank, A. Gheorghiu, P. Lagarde, A.L. Theye, Philos. Mag. Lett. 59, 9 (1989).

[3] D. Udron, A.M. Theye, D. Raoux, A.M. Flank, P. Lagarde, J.P. Gaspard, J. Non-Cryst. Solids 137\&138, 131 (1991).

[4] A. Burian, P. Lecante, A. Mosset, J. Galy, Z. Kristallogr. 193, 199 (1990).

[5] A. Burian, P. Lecante, A. Mosset, J. Galy, J. Mater. Sci, in press.

[6] B.K. Teo, EXAFS: Basic Principles and Data Analysis, Springer-Verlag, Berlin 1986.

[7] A. Burian, P. Lecante, A. Mosset, J. Galy, submitted to Int. J. Mater. Product Technol.

[8] A. Burian, P. Lecante, A. Mosset, J. Galy, submitted to Philos. Mag. B.

[9] P.A. Lee, G. Beni, Phys. Rev. B 15, 2882 (1977).

[10] T.A. Carlson, Photoelectron and Auger Spectroscopy, Plenum, New York 1975.

[11] E.S. Stern, B. Bunker, S.M. Heald, in: EXAFS Spectroscopy: Techniques and Applications, Eds. B.K. Teo, D.C. Joy, Plenum, New York 1981. 